\title{
Challenges for Insured Patients in Accessing Behavioral Health Care
}

\author{
MariaElena O. Williams, MD \\ Jamie R. Gilroy, BA \\ Tae Y. Chang, BA \\ Deborab J. Seymour, PsyD \\ Department of Family Medicine, University \\ of Colorado School of Medicine, Denver, \\ Colorado
}

Conflicts of interest: authors report none.

\section{CORRESPONDING AUTHOR}

Deborah Seymour, PsyD

Dept. of Family Medicine

University of Colorado School of Medicine

Mail Stop F-496

Academic Office 1, Room 3617

12631 East 17th Ave.

Aurora, CO 80045

Deb.Seymour@ucdenver.edu

\begin{abstract}
The Patient Protection and Affordable Care Act (ACA) mandates that health insurance plans include sufficient access to behavioral health providers, but lacks specific guidelines to define sufficient access. Using a secret shopper methodology, we called behavioral health providers in the Denver metropolitan area networked with 3 large insurance companies. We found that, depending on insurance company and level of training, $9.8 \%$ to $59 \%$ of providers could offer a new patient appointment, with psychiatry appointments being particularly difficult to schedule. These findings are consistent with similar studies conducted in other regions, suggesting that access to outpatient behavioral health care is limited despite existing ACA regulations.
\end{abstract}

Ann Fam Med 2017;15:363-365. https://doi.org/10.1370/afm.2092.

\section{INTRODUCTION}

M ore than one-half of Americans struggle with a mental health condition in their lifetime $e^{1}$ and in 2014 alone, $18.1 \%$ of all US adults experienced a form of mental illness. ${ }^{2}$ Under the Patient Protection and Affordable Care Act (ACA), health insurance plans must include mental health services as an essential health benefit. But are these services accessible to those who need them?

Network adequacy, a health plan's ability to offer access to primary and specialty health care providers, is crucial to ensuring access to services. Under the ACA a plan must "maintain a network that is sufficient in numbers and types of providers, including providers that specialize in mental health and substance abuse services, to assure that all services will be accessible without unreasonable delay." ${ }^{\prime 3}$ The federal requirements, however, do not specify what constitutes a "sufficient" number of providers or "unreasonable delay," giving each state the power to define and enforce these requirements. Our study examines access to outpatient behavioral health care in 1 major metropolitan area after implementation of the Affordable Care Act.

\section{METHODS}

The project used a secret shopper methodology, which has been successfully used in other studies evaluating access to health care. ${ }^{4-6}$ Three researchers made scripted telephone calls to all behavioral health providers within 20 miles of central Denver who were listed in the online insurance directories of Anthem BlueCross BlueShield, United Healthcare, and Cigna. These companies are the largest insurance providers in Colorado that offer preferred provider organization (PPO) plans through Colorado's Health Insurance Marketplace. ${ }^{7}$ The researchers posed as potential patients with mild to moderate depression and inquired about the next available appointment date. Data were collected and organized as summarized in Figure 1. This research was approved by the Colorado Multiple Institutional Review Board. 


\section{Figure 1. Method used to organize data collected from phone calls} to behavioral health care providers.

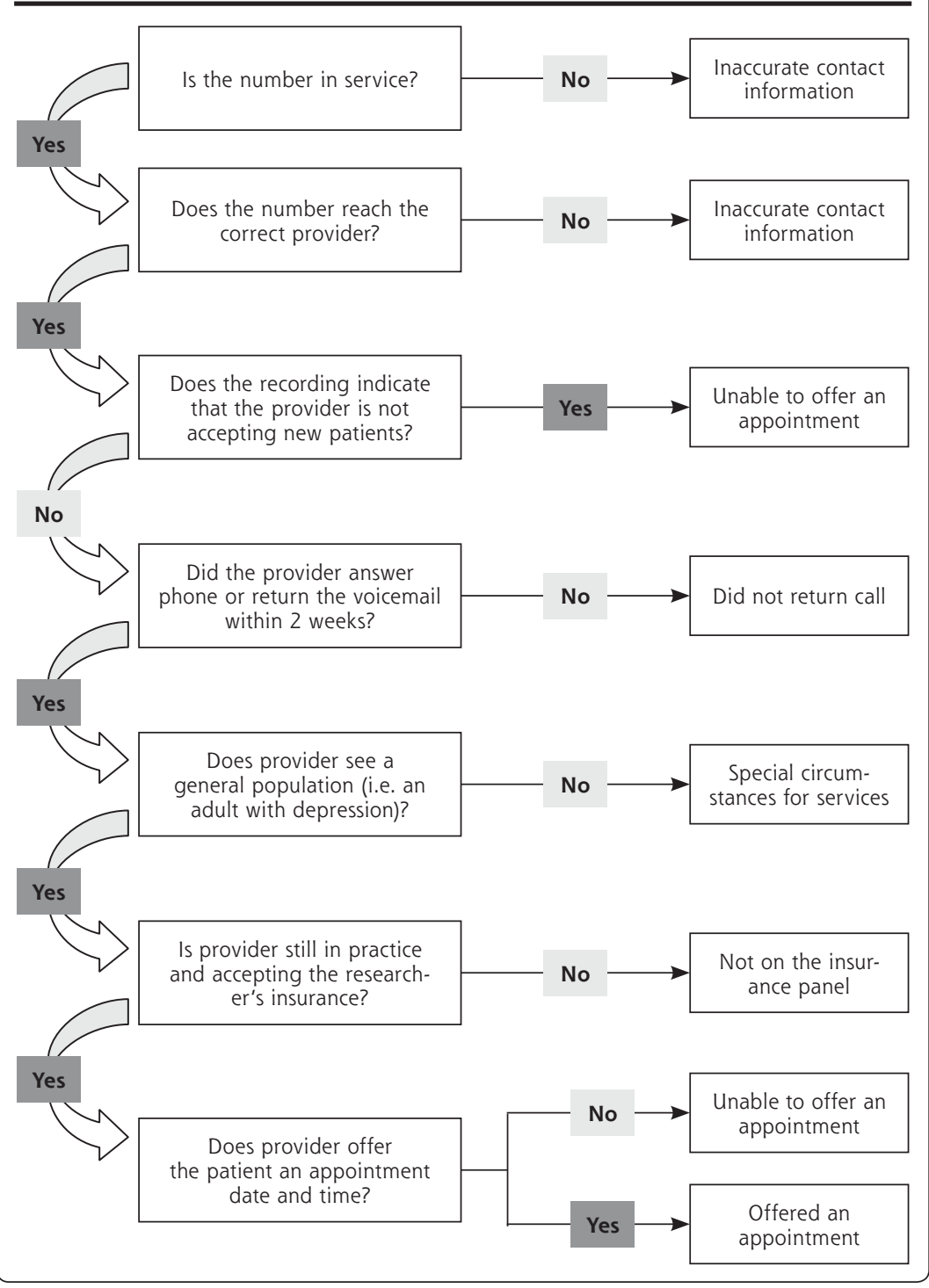

\section{RESULTS}

Researchers made 1,932 calls to behavioral health providers included in the networks of the insurance companies listed above in 2014-2015. Across the 3 insurance companies, $13.0 \%$ of directory entries were inaccurate. Only $43.6 \%$ of all calls and $9.8 \%$ to $13.6 \%$ of calls to psychiatrists yielded appointments. Table 1 details the outcomes of these calls.

\section{DISCUSSION}

Despite the provisions of the Affordable Care Act, access to behavioral health care remains limited for private insurance holders. Our data suggest that a patient in the Denver area would need to call 7 to 10 psychiatrists, depending on the insurance company, to find an available appointment. In addition, the directories had numerous inaccuracies including incorrect contact information for providers and listings of providers who had left the networks covered by the directories.

Our findings build on those from similar studies conducted in other regions. The Mental Health Association of Maryland found in 2013 that only $13.5 \%$ of outpatient psychiatrists on private insurance panels surveyed could offer an appointment. ${ }^{4}$ The Mental Health

Table 1. Results of Telephone Calls Made to Behavioral Health Care Providers

\begin{tabular}{|c|c|c|c|c|c|c|}
\hline \multirow[b]{3}{*}{ Carrier } & \multicolumn{6}{|c|}{ Type of Provider Called } \\
\hline & \multicolumn{3}{|c|}{ Psychiatrist } & \multicolumn{3}{|c|}{ Psychologist } \\
\hline & A & B & $\mathbf{C}$ & A & B & $\mathbf{C}$ \\
\hline Inaccurate contact information, No. (\%) & $19(32.2)$ & $17(21.3)$ & 7 (11.5) & $28(17.6)$ & $20(11.1)$ & $13(6.6)$ \\
\hline Not on the insurance panel, No. (\%) & $1(1.7)$ & $1(1.3)$ & $2(3.3)$ & $6(3.8)$ & $10(5.6)$ & $8(4.1)$ \\
\hline Special circumstances for services, ${ }^{b}$ No. (\%) & $1(1.7)$ & $10(12.5)$ & $10(16.4)$ & $6(3.8)$ & $8(4.4)$ & $12(6.1)$ \\
\hline Did not return call, No. (\%) & $10(16.9)$ & $10(12.5)$ & $19(31.1)$ & $27(17.0)$ & $28(15.6)$ & $35(17.8)$ \\
\hline Unable to offer an appointment, No. (\%) & $20(33.9)$ & $33(41.3)$ & $17(27.9)$ & $37(23.3)$ & $27(15.0)$ & $39(19.8)$ \\
\hline Offered an appointment, No. (\%) & $8(13.6)$ & $9(11.3)$ & $6(9.8)$ & $55(34.6)$ & $87(48.3)$ & $90(45.7)$ \\
\hline Total calls made & 59 & 80 & 61 & 159 & 180 & 197 \\
\hline
\end{tabular}


Association in New Jersey found that 33\% of psychiatrists had incorrect contact information in the insurance directories and that although $51 \%$ of psychiatrists were taking new patients, nearly one-half of them were booked more than 1 month out. ${ }^{5}$ Additionally, our results mirror findings from a 2015 California study of access to primary care that found numerous errors in network directories and reported an appointment rate of $31 \%$ for calls to Marketplace plan providers, indicating that network inadequacy extends beyond the realm of behavioral health care.

To our knowledge, this study provides the first quantitative look at access to behavioral health care in Colorado since implementation of the Affordable Care Act. Insured patients continue to face multiple challenges when attempting to use behavioral health services due to network inadequacy as well as other factors, including the low percentage of psychiatrists accepting insurance (55\%) and the decline in number of practicing psychiatrists in the United States. ${ }^{8}$ Given the stigma and fatigue associated with mental illness, the lengths patients must go to obtain an appointment are particularly concerning.

Since we conducted our study, federal guidelines were added that require monthly directory updates, ${ }^{9}$ which we hope will reduce the number of directory inaccuracies. Despite this, we believe that the nonspecific requirements outlined in the Affordable Care Act regarding network adequacy remain insufficient and require further delineation and regulation with longitudinal monitoring of progress to ensure that the 1 in 6 Americans suffering from mental illness each year can access appropriate and timely care.

Limitations of the study include our using 3 different secret shoppers, although any differences in approach were mitigated by using a uniform, IRB-approved script, and our surveying carriers at different times (Carrier $\mathrm{C}$ in 2014 and Carriers A and B in 2015). Given that the network adequacy legislation changed little during this time, we believe the data are comparable.

To read or post commentaries in response to this article, see it online at http://www.AnnFamMed.org/content/15/4/363.

Key words: behavioral medicine; access to health care; Affordable Care Act; preferred provider organizations

Submitted November 1, 2016; submitted, revised, January 30, 2017; accepted February 19, 2017.

Funding support: Funding for this study was provided by the Department of Family Medicine, University of Colorado School of Medicine.

Previous presentations: Poster presented at the Shared Networks of Colorado Ambulatory Practices and Partners Conference; September 25-26, 2015; Colorado; and the Collaborative Family Healthcare Association National Conference; October 15-17, 2015; Portland, Oregon.

Acknowledgments: We appreciate the guidance of Larry A. Green, MD, in our preparation of this manuscript and the assistance of the University of Colorado Department of Family Medicine, William LeBlanc, $\mathrm{PhD}$, and Lynn VanderWielen, PhD, in conducting this study and analyzing the results.

\section{References}

1. Harvard Medical School Department of Health Care Policy. National Comorbidity Survey Replication (NCS-R). Harvard Medical School; 2005. http://www.hcp.med.harvard.edu/ncs/index.php. Accessed Jul 18, 2016.

2. Center for Behavioral Health Statistics and Quality. Behavioral health trends in the United States: results from the 2014 National Survey on Drug Use and Health. National Institute of Mental Health; 2015. http://www.nimh.nih.gov/health/statistics/prevalence/any-mentalillness-ami-among-us-adults.shtml. Accessed Jul 18, 2016.

3. Network Adequacy Standards, 45 C.F.R. Sect. 156.230 (2012).

4. Mental Health Association of Maryland. Access to psychiatrists in 2014 qualified health plans. MHAMD; 2015. https://www.mhamd. org/wp-content/uploads/2014/01/2014-QHP-Psychiatric-NetworkAdequacy-Report.pdf. Accessed Mar 7, 2015.

5. Mental Health Association in New Jersey. Managed care network adequacy report. MHANJ; 2015. http://www.mhanj.org/wp-content/ uploads/2014/09/Network-Adequacy-Report-Final.pdf, Accessed June 11, 2015.

6. Haeder SF, Weimer DL, Mukamel DB. Secret shoppers find access to providers and network accuracy lacking for those in marketplace and commercial plans. Health Aff (Millwood). 2016;35(7):1160-1166.

7. Colorado Department of Regulatory Agencies, Division of Insurance. Health insurance cost report to the Colorado General Assembly for calendar year 2014. Colorado Department of Education; 2016. http://www2.cde.state.co.us/artemis/regserials/reg420internet/reg4202013internet.pdf. Accessed Apr 23, 2106.

8. Bishop TF, Seirup JK, Pincus HA, Ross JS. Population of US practicing psychiatrists declined, 2003-13, which may help explain poor access to mental health care. Health Aff (Millwood). 2016;35(7):1271-1277.

9. Center for Consumer Information and Insurance Oversight and Centers for Medicare $\&$ Medicaid Services. Final 2016 letter to issuers in the federally-facilitated marketplaces CMS; 2015 Feb 20. https://www.cms.gov/CCIIO/Resources/ Regulations-and-Guidance/Downloads/2016-Letterto-Issuers-2-20-2015-R.pdf. Accessed Jul 18, 2016. 